\title{
Massive Fecal Impaction with Megarectum Formation: A Case Report
}

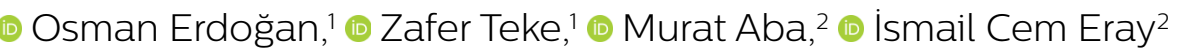

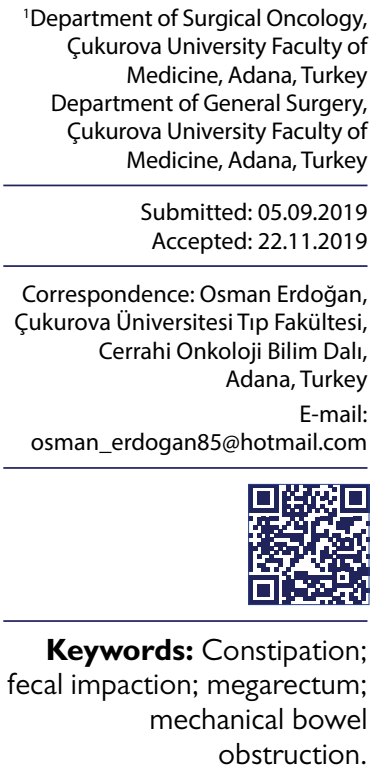

Correspondence: Osman Erdoğan, Çukurova Üniversitesi Tıp Fakültesi, Cerrahi Onkoloji Bilim Dalı Adana, Turkey E-mail: osman_erdogan85@hotmail.com

Keywords: Constipation; fecal impaction; megarectum; mechanical bowel obstruction.

\begin{abstract}
Fecal impaction occurs because of hardened fecal matter retained in the colorectum which cannot be evacuated by peristaltic activity. Fecal impaction commonly occurs among nursing home residents, patients with neurological deficit, psychiatric disease or renal failure. Fecal impaction is usually treated by manual disimpaction, enemas and laxatives. Laparotomy is required only in the presence of complications. We herein report a case of a massive fecal impaction with megarectum in a 62-year-old woman who presented with large bowel obstruction. The aim of this report is to give a brief review of this entity and discuss the treatment options for these cases.
\end{abstract}

\section{INTRODUCTION}

Fecal impaction occurs because of hardened fecal matter retained in the colon and rectum which cannot be evacuated by regular peristaltic activity. If this is not recognized and treated early, it can give rise to the formation of fecoliths, or stone-like feces. Fecal impaction is a cause for increased morbidity and a significant cause of a decrease in quality of life among the elderly. ${ }^{[1,2]}$

We herein report a case of a massive fecal impaction with megarectum in a 62-year-old woman who presented with symptoms of mechanical bowel obstruction. The objective of this article is to give a concise review of this condition and discuss the treatment strategies for these cases.

\section{CASE REPORT}

A 62-year-old female was admitted to our institute with complaints of abdominal pain, abdominal distention, and the absence of gas-feces discharge for approximately seven to ten days. She had a 2-year history of chronic constipa- tion. Her past medical history also included a neurogenic bladder. On physical examination, abdomen was distended, with no guarding. The bowel sounds were hypoactive. Digital rectal examination revealed a large amount of hard impacted feces. White blood cell count was $15.310^{3} / \mu \mathrm{L}$. Plain abdominal $X$-ray revealed a distended colorectum with a large amount of feces in the rectum. A computed tomography (CT) of the abdomen showed distended colonic segments filled with intraluminal fecal residue that appeared organized in the rectum forming massive fecal impaction producing a megarectum (Fig. I). Initially, a combination of medical strategies were tried including manual disimpaction, laxatives, enemas and rectosigmoidoscopic examination, but none of them were successful in resolving the fecal impaction. Since our patient was unresponsive to conventional medical treatment, we decided to perform a surgical intervention. After an adequate resuscitation with fluids and electrolytes, a laparotomy was performed. At operation, a megarectum, $12 \mathrm{~cm}$ in diameter, impacted with a vast amount of feces was observed (Fig. 2). A longitudinal rectosigmoid colotomy was performed and the rectum was instrumentally evacuated (Fig. 3). Then, the 


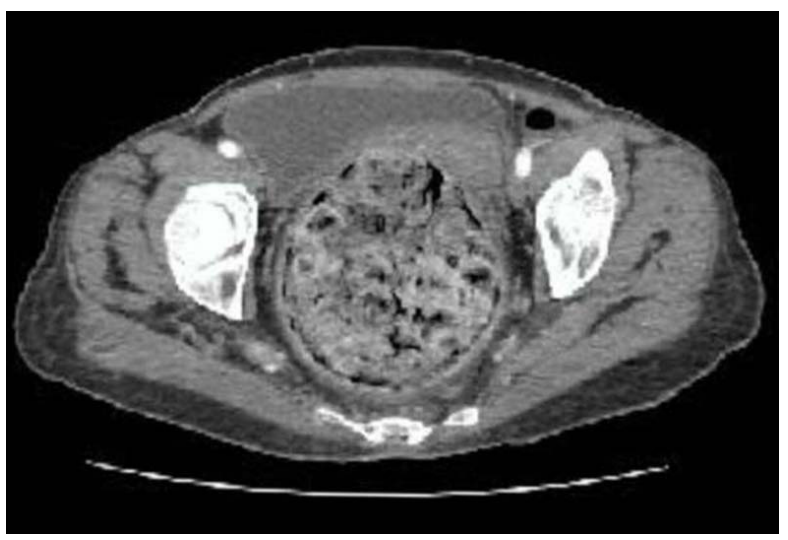

Figure 1. Axial contrast-enhanced pelvic computed tomography scan showing a voluminous fecal impaction with rectal dilatation reaching $12 \mathrm{~cm}$ in diameter.

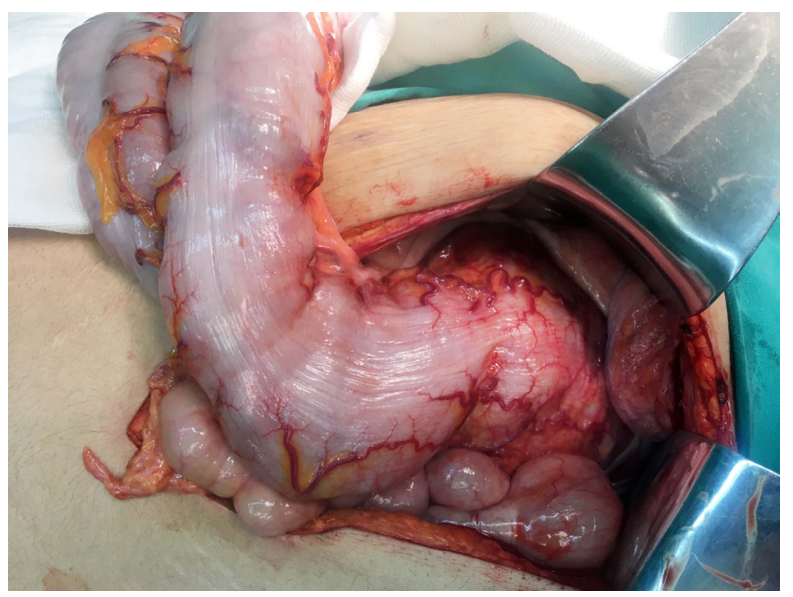

Figure 2. Intraoperative view of megarectum during laparotomy.

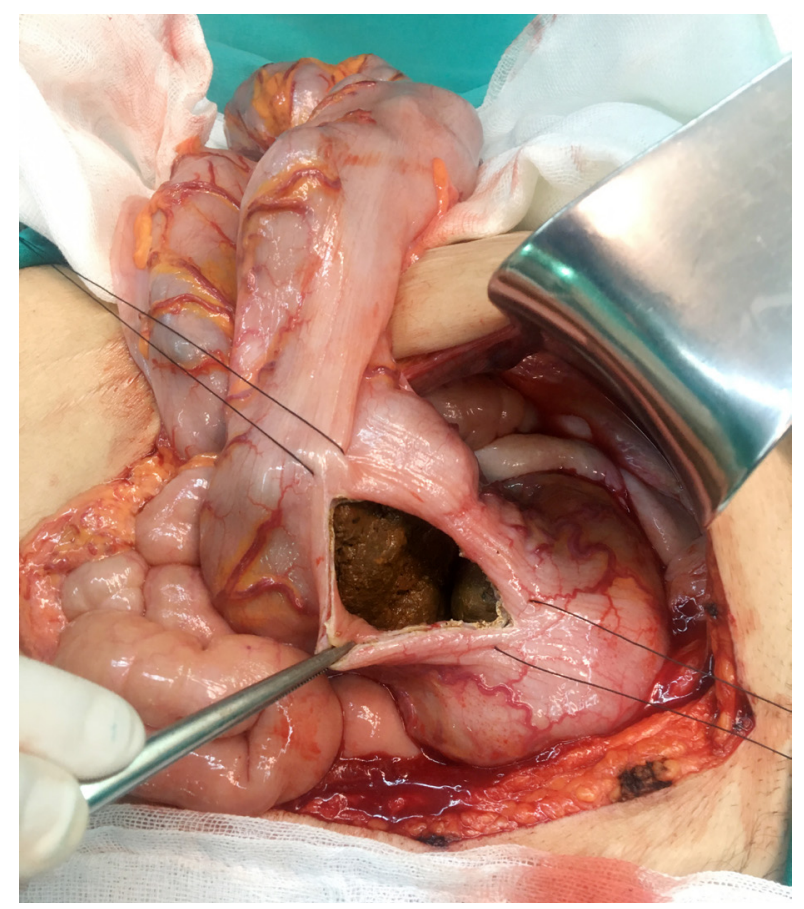

Figure 3. Massive fecal impaction resided in the rectosigmoid on opening the bowel. proximal sigmoid colon used to fashion the loop colostomy. A full-thickness biopsy was taken from the anorectal junction. The postoperative course was uneventful. The pathological report of the biopsy revealed the nerve plexuses with ganglion cells. The measurement of colonic transit time was performed with radiopaque markers, and the result of the test was within the normal limit. The presence of the rectoanal inhibitory reflex was demonstrated, which excluded Hirschsprung's disease. An improvement occurred in bowel diameter in time. The colostomy was closed after intraoperative colonoscopy revealed normal findings.

\section{DISCUSSION}

Fecal impaction commonly occurs among the elderly who are hospitalized patients or under institutional care. It is associated with scleroderma, chronic renal failure, congenital abnormalities in the anorectal region or previous surgical procedure. In older adults who regularly consume non-steroidal anti-inflammatory drugs, a higher occurrence of fecal impaction has been reported. Among hospitalized patients, administration of medications with an opioid can result in fecal impaction in the elderly, especially in those who have a history of chronic constipation and are bed-bound. ${ }^{[3,4]}$

Fecal impaction has three main predisposing factors: (I) bad eating habits, (II) decreased colon motility and rectal sensitivity, (III) failure to meet the need for defecation as soon as felt due to immobilization, dementia, depression or physical weakness. ${ }^{[5]}$ Severe constipation is a significant problem that affects almost $70 \%$ of elderly people who are under care in nursing homes. Fecal impaction is more common among older women who are in institutional care and have associated neuropsychiatric disorders. ${ }^{[6-8]}$ Our patient was a 62-year-old female with chronic constipation and neurogenic bladder.

Patients with fecal impaction often give a history of inability to evacuate stools spontaneously and complain of total constipation. In most instances, an associated history of progressive abdominal distension with increasing abdominal discomfort or pain is present. Physical examination findings often reveal a distended abdomen. Hard fecal mass may be palpable along the colon. The diagnosis of fecal impaction is primarily based on clinical signs. A detailed history of bowel habits and a thorough physical examination which includes a digital rectal examination is mandatory. Our patient had a 2-year history of chronic constipation, and her physical examination exhibited a distended abdomen, while digital rectal examination revealed hard fecal impaction.

A digital rectal examination is mandatory as the first diagnostic evaluation to confirm the diagnosis of fecal impaction. When a rectal exam does not reveal fecal impaction or hard fecal masses in the rectum, the possibility of fecal impaction more proximal in the bowel or other causes, such as strictures or volvulus of the colon, should be con- 
sidered. The most useful and commonly used radiological imaging for evaluation is a CT of the abdomen with oral or rectal contrast. A plain x-ray of the abdomen can, at times, reveal fecal overloading of the colon with colonic distention in the segment proximal to the region of fecal impaction. Rarely, a contrast enema or sigmoidoscopy are indicated in a patient who has no history suggestive of the colonic disease. A CT scan showed massive fecal impaction producing a megarectum with proximal colonic distention in our patient.

The medical treatment options are digital evacuation of the impacted fecal mass, the rectal administration of stool softening agents, usually enemas or suppositories, and orally administered laxatives, such as polyethylene glycol (PEG) 3350 with electrolytes. ${ }^{[1,9,10]}$ In many cases, manual disimpaction is required. The procedure is done using lubrication and gently removing the impacted stool with the index finger, and can be aided with the use of an anoscope and suction. Manual evacuation can be done under general anesthesia. After removal of the impaction, the patient should be placed on additional stool softeners and laxatives and advised on the importance of regular bowel movements. The rectal impacted feces can be removed using the single or multiple Foley technique. The threeway Foley catheter is passed into the rectum and gently inflated and pulled back to retrieve rectal fecal mass. This technique has the potential risk of causing perforation in an already thin-walled rectum. ${ }^{[1]}$

If the abdominal $x$-ray reveals that the fecal impaction is located distally, then the use of enemas (vegetable oil, mineral oil, glycerin, liquid vaseline, tap water, phosphate or soapsuds) or suppositories (glycerin or bisacodyl) can be helpful. They induce bowel movements by softening hard stool and by stimulating colonic muscle contraction in response to rectal and colonic distention. Maintenance treatment is started after 6 days of disimpaction treatment and consists of orally administered PEG 3350 with electrolytes for $>2$ weeks (follow-up period). ${ }^{[2]}$

A variety of enema bag kits and enema solutions are commercially available for use. In clinical practice, vegetable oil enema ( $200 \mathrm{~mL}$ olive oil in $1000 \mathrm{~mL}$ of water), glycerin enema ( $200 \mathrm{~mL}$ glycerin in $1000 \mathrm{~mL}$ of water), liquid vaseline enema ( $200 \mathrm{~mL}$ liquid vaseline in $1000 \mathrm{~mL}$ of water), mineral oil enema (100 mL/day), tap water enema $(500 \mathrm{~mL} /$ day), phosphate enema ( $120 \mathrm{mg} /$ day), and soapsuds enema $(1500 \mathrm{~mL} /$ day-30 gr soap in $1000 \mathrm{~mL}$ of water ) are commonly used rectal enemas. The volume of an enema should be carefully controlled. Rarely more than $500 \mathrm{~mL}$ of enema fluid is required, and $I$ to $2 L$ should be the absolute limit at once. The fluid flow rate is adjusted to $75-100 \mathrm{~mL} / \mathrm{min}$. An oil retention enema ( $120 \mathrm{~mL}$ vegetable oil), followed by a tap water enema $(500 \mathrm{~mL} /$ day), is generally preferable to salt-containing enemas (phosphate and soapsuds enemas) because oil and water are less irritating to the rectal mucosa. Bisacodyl suppositories or phosphate enemas may also be used to empty the rectum if the stool is relatively soft. If the stool is very hard, then a small-volume $(60 \mathrm{~mL})$ rectal oil enema may be used first. Gentle, low-volume enemas can be used through colostomies by experienced nurses. Enemas should be used cautiously in patients with a history of bowel stricture or recent lower bowel surgery and in immunocompromised patients. The fluid constituents should be mild and nontoxic. Tap-water enemas made with potable water involve few complications. Injury of the mucosa of the lower intestine has occurred from such innocent substances as soapsuds. Salt-containing enemas may be harmful in patients with heart disease.

Rectally administered solutions mechanically soften the impacted stool and the additional volume gently stimulates the rectum to evacuate. During enema administration, the patient is placed in the left lateral decubitus position with the buttocks close to the edge of the bed and the left leg straight and the right leg bent at knee toward the chest (Sims' position) with a plastic bag under the hips. The enema can be given using a 30-French red rubber catheter or three-way Foley. Once the Foley catheter is passed into the rectum, the balloon is then slowly inflated with 10 to $30 \mathrm{~mL}$ of water using a syringe. The inflated Foley catheter balloon allows the administrator to maintain a seal against the patient's anus for prolonged enema contact. The pressure and volume of enema administration must be appropriate. Enema pressure is controlled by the height of the solution reservoir. Limiting the reservoir height to 45 to $60 \mathrm{~cm}$ above the anus maintains an adequate pressure limit. The volume and rate of fluid administration is guided by the size of the patient's rectum and the degree of fullness symptoms. Administration of smaller volumes ( $I$ to $2 \mathrm{~L}$ ) may be more beneficial than a single large volume enema. A slower rate of enema administration produces less patient discomfort, aids in mixing of solution, and allows instillation of a larger volume. ${ }^{[13]}$ The patient's sensation of fullness is a helpful guide during enema instillation. Volumes or rates that produce patient discomfort are avoided. ${ }^{[1,15]}$ Once administration is complete, a few minutes are allowed for the solution to mix with and soften the stool. Gentle massaging of the lower abdomen may aid in mixing the combination. The patient then voluntarily evacuates the enema-stool mixture. ${ }^{[13]}$ Additional gentle abdominal manipulation often helps in evacuation. Ambulatory patients can evacuate more efficiently by using a commode. This process is repeated until the symptoms are relieved and returns are clear. ${ }^{[1,15]}$

Most ready-to-use enema solutions contain water and an osmotic agent. One such combination contains water, sodium dihydrogen phosphate and disodium hydrogen phosphate. After manual disimpaction, a phosphate enema (B.T. Enema ${ }^{\circledR}$ solution, $135 \mathrm{~mL}$ or $210 \mathrm{~mL}$ for adults; Yenişehir Lab., Ankara, Turkey) is given once daily for the first three days or if necessary, for a maximum of seven days. When applying the rectal enema, the solution should be allowed to remain in the intestine for 5 to 10 minutes. To do this, the hips are pressed against each other and pressure is applied to the anal area. This saline laxative is an intestinal evacuant that increases the amount of water in the fe- 
ces and thus helps to empty stool. Saline laxatives provide water retention in the sigmoid colon. As a result of this effect, the intestine is stimulated and evacuated within 2 to 5 minutes. Stool excretion will be watery with the application, so plenty of fluid should be taken to prevent fluid loss in the body. No more than one bottle is used per day. Saline laxative enemas should not be used for more than two weeks. If phosphate enema remains in the rectum for a long time, it may lead to hyperphosphatemia and electrolyte abnormalities.

For proximal fecal impaction, the ideal laxatives are PEG and magnesium citrate. Proximal softening or washout oral lavage with PEG 3350 solutions containing electrolytes (GOLYTELY ${ }^{\circledR}$; Braintree Laboratories, West Braintree, MA, USA) can be used to soften or washout proximal stool. ${ }^{[6]}$ This technique is contraindicated when a complete bowel obstruction exists. The volume and rate of oral lavage is dependent on patient size. To treat adult fecal impaction, oral regimens vary from I to $2 \mathrm{~L}$ of PEG with electrolytes or $17 \mathrm{~g}$ of PEG 3350 in 120 to $240 \mathrm{~mL}$ of water every 15 minutes until the patient begins passing stool or eight glasses have been consumed. ${ }^{[15]}$ Development of nausea, vomiting, or significant abdominal discomfort prompts cessation of fluid intake. A recent Cochrane Review evaluated 10 randomized controlled trials comparing lactulose to PEG. The study involving 868 participants with age range from 3 months to 70 years showed higher weekly stool frequency and improved abdominal pain scores for patients using PEG. ${ }^{[17]}$ Osmotic laxatives such as oral magnesium citrate can be used for proximal lavage. Thirty to $60 \mathrm{~mL}$ of magnesium citrate orally with $120 \mathrm{~mL}$ of clear liquids every 4 to 8 hours is a common regimen. Magnesium-containing and phosphate-containing solutions must be used with extreme caution in patients with renal insufficiency and congestive heart failure.

Administration of an appropriate laxative or fiber supplement with increased intake of water after the evacuation of the impacted fecal mass is required to prevent recurrence. Once fecal impaction has been resolved, the cause should be explored. After a bowel preparation, a barium enema or a screening colonoscopy should be performed. Thyroid and metabolic profiles should be evaluated. Other factors that need to be corrected include depression, lack of exercise, and inadequate access to toilet facilities.

Complications of fecal impaction include stercoral ulceration, rectosigmoid bleeding, perforation, peritonitis, urinary tract infections and obstructive uropathy. Other less seen complications are autonomic dysreflexia, neurological events, volvulus, pneumothorax, shock, cardiopulmonary collapse, and death. ${ }^{[18]}$

Severe fecal impaction or failure of medical measures may necessitate surgery. Early surgical evaluation and intervention are necessary if there are associated signs of peritonitis. Laparotomy is indicated only if complications such as complete mechanical bowel obstruction or stercoral ulcer perforation develop. ${ }^{[19,20]}$ Surgical intervention involves either explorative laparotomy or laparoscopy followed by a colotomy with extraction of fecal matter or excision of the involved colonic segment if there is an underlying pathology. ${ }^{[21,22]}$ At operation, a megarectum, and even megasigmoid, impacted with a massive amount of feces is found. It usually appears paper-thin and dusky-gray. The rectum has to be manually disimpacted if a low Hartmann's procedure, using a TA-90 linear stapler, will be performed. If this is the case, the sigmoid colon is used to fashion the end colostomy. In patients with a limited disease, for example sigmoid megacolon, a partial resection has favorable results. ${ }^{[23]} \mathrm{A}$ more radical surgery such as a total abdominal colectomy with ileorectal anastomosis may be necessary in patients with functional constipation due to total colonic inertia. Preferably, if the proximal colon is full of fecal matter, it should be washed by PEG or by rapid on-table colonic lavage before resection. Since our patient was unresponsive to conventional medical treatment, we performed a rectosigmoid colotomy, instrumental disimpaction, and fecal diversion with loop sigmoid colostomy in the emergency setting.

If idiopathic megarectum is responsible for functional constipation in these patients, proctectomy should be curative. The rapid reduction in the need for cathartic agents after rectal resection suggests that the principal determinant for ongoing fecal retention in this patient population is the megarectum itself. Once the diagnosis of megarectum is made, surgery should not be delayed; because conservative therapy not only fails, but it may have significant psychological and physical morbidity. ${ }^{[24]}$ The surgical options for idiopathic megarectum or megacolon include (I) subtotal colectomy with ileosigmoid anastomosis or ileorectal anastomosis or cecorectal anastomosis, (2) segmental colectomy (sigmoid colectomy, left hemicolectomy, partial colectomy), (3) rectal procedures (anterior resection with colorectal anastomosis, proctectomy with coloanal anastomosis or colonic J pouch formation, Swenson endorectal pull-through, Duhamel procedure, vertical reduction rectoplasty, restorative proctocolectomy with J-pouch formation), (4) pelvic floor procedures (internal sphincterotomy, lateral division of the puborectalis muscle), and (5) fecal diversion (temporary ileostomy formation, colostomy formation). Both the Swenson and Duhamel procedures involve a proctectomy. The Swenson procedure was the original pull-through procedure used to treat Hirschsprung's disease. The aganglionic segment is resected down to the sigmoid colon and rectum, and an oblique anastomosis is performed between the normal colon and the low rectum. The Swenson procedure involves endorectal pull-through of the descending or sigmoid colon down to the perineum. Similarly, the Duhamel procedure was initially described in patients with Hirschsprung's disease and has subsequently been applied to patients with idiopathic megarectum. It involves excision of the dilated rectum and oversewing of the distal rectal stump via an abdominal approach, followed by creation of an end-to-side anastomosis of the proximal bowel to the posterior aspect of the rectal stump via a perineal approach. 
Gladman et al. ${ }^{[25]}$ evaluated the outcomes of all surgical options for idiopathic megarectum or megacolon in their systematic review. They made following recommendations: (I) In patients with megacolon with a nondilated functional rectum, subtotal colectomy and ileorectal anastomosis is the procedure of choice as segmental resection results in higher incidence of postoperative constipation. However, patients must be counseled that this procedure is associated with a definite mortality and a $20 \%$ morbidity that frequently requires further surgical intervention and which is most commonly secondary to bowel obstruction. (2) In patients with dilatation affecting the whole of the colon and rectum (mega bowel), the most appropriate procedure appears to be a restorative proctocolectomy with ileal pouch reconstruction. Success rates appear to be in the region of $70 \%$ to $80 \%$, although the procedure is complex and patients should be warned of the risk of suboptimal pouch function, characterized by frequency of defecation and nocturnal fecal soiling. (3) In patients with only distal dilatation of the bowel (megarectum+megasigmoid), there appears to be very little to choose between vertical reduction rectoplasty and proctectomy with coloanal anastomosis in terms of success rates (70\%-80\%). However, the mortality associated with proctectomy suggests that vertical reduction rectoplasty, which involves less-radical pelvic dissection, is a safer alternative in such patients, although results of this procedure are currently only limited to small numbers of patients and with limited follow-up. (4) The Duhamel and endorectal pull-through procedures cannot be recommended because of their variable results and unacceptably high morbidity, with many patients requiring further surgery for complications or persistent constipation. To date, the pelvic-floor procedures evaluated for mega bowel are completely ineffective. (5) The final option in patients wishing to avoid the risks of these complex procedures is the creation of a stoma. It also provides an alternative when other procedures have not been successful. However, this should be created proximal to the dilated/dysfunctional bowel, and patients should be warned that it may not address symptoms of abdominal pain and distension.

It is clear that the surgical management of mega bowel is complex and should be reserved for patients with intractable symptoms with impaired quality of life who have failed or cannot tolerate nonsurgical management. This should preferably be performed in a specialist surgical unit and involve a multidisciplinary approach as patients require comprehensive clinical, psychologic, and physiologic evaluation and frequently have coexisting urologic dysfunction. ${ }^{[26]}$ Currently, no form of surgical intervention offers a $100 \%$ cure rate, and preoperative counseling before surgery is obligatory so that patients can understand that surgery may only improve rather than cure symptoms, or that in the event of surgical failure, they may subsequently require a permanent stoma.

\section{CONCLUSION}

We conclude that neglected fecal impaction may lead to a megarectum causing a mechanical bowel obstruction or even colorectal perforation. Fecal impaction is a significant but preventable problem in the elderly population within hospitals and other institutions. The best way to treat is to prevent it from developing in the first place. The cause of constipation should be identified early and managed appropriately. These patients are encouraged to change their lifestyle, drink plenty of water, exercise, and eat a high fiber diet to prevent constipation.

\section{Informed Consent}

Written informed consent was obtained from the patient for the publication of the case report and the accompanying images.

\section{Peer-review}

Internally peer-reviewed.

Authorship Contributions

Concept: O.E., Z.T.; Design: O.E., Z.T.; Supervision: O.E., Z.T., I.C.E.; Fundings: O.E., M.A., I.C.E.; Materials: O.E., M.A., I.C.E.; Data: O.E., M.A., I.C.E.; Analysis: O.E., Z.T., M.A., I.C.E.; Literature search: O.E., Z.T.; Writing: O.E., Z.T.; Critical revision: O.E., Z.T., M.A., I.C.E.

Conflict of Interest

None declared.

\section{REFERENCES}

1. García Cabrera AM, Jiménez Rodríguez RM, Reyes Díaz ML, Vázquez Monchul JM, Ramos Fernández M, Díaz Pavón JM, Palacios González C, Padillo Ruiz FJ, de la Portilla de Juan F. Fecal incontinence in older patients. A narrative review. Cir Esp 2018;96:131-7. [Article in English, Spanish] [CrossRef]

2. Poitras R, Warren D, Oyogoa S. Opioid drugs and stercoral perforation of the colon: Case report and review of literature. Int J Surg Case Rep 2018;42:94-7. [CrossRef]

3. Osterman MT, Foley C, Matthias I. Clozapine-induced acute gastrointestinal necrosis: a case report. J Med Case Rep 2017;11:270.

4. Wickham RJ. Managing Constipation in Adults With Cancer. J Adv Pract Oncol 2017;8:149-61. [CrossRef]

5. Wrenn K. Fecal impaction. N Engl J Med 1989;321:658-62. [CrossRef]

6. Serrano Falcón B, Álvarez Sánchez Á, Diaz-Rubio M, Rey E. Prevalence and factors associated with faecal impaction in the Spanish old population. Age Ageing 2017;46:119-24. [CrossRef]

7. Serrano Falcón B, Barceló López M, Mateos Muñoz B, Álvarez Sánchez A, Rey E. Fecal impaction: a systematic review of its medical complications. BMC Geriatr 2016;16:4. [CrossRef]

8. Corban C, Sommers T, Sengupta N, Jones M, Cheng V, Friedlander E, et al. Fecal Impaction in the Emergency Department: An Analysis of Frequency and Associated Charges in 2011. J Clin Gastroenterol 2016;50:572-7. [CrossRef]

9. Reck-Burneo CA, Vilanova-Sanchez A, Gasior AC, Dingemans AJM, Lane VA, Dyckes R, et al. A structured bowel management program for patients with severe functional constipation can help decrease emergency department visits, hospital admissions, and healthcare costs. J Pediatr Surg 2018;53:1737-41. [CrossRef]

10. Gidwaney NG, Bajpai M, Chokhavatia SS. Gastrointestinal Dysmotility in the Elderly. J Clin Gastroenterol 2016;50:819-27. [CrossRef]

11. Ratnapala DN, Borrowdale RC, Lambrianides AL. On-table technique for removing faecalomas from the rectal stump before restora- 
tion of intestinal continuity. ANZ J Surg 2008;78:623. [CrossRef]

12. Bekkali NL, van den Berg MM, Dijkgraaf MG, van Wijk MP, Bongers ME, Liem O, et al. Rectal fecal impaction treatment in childhood constipation: enemas versus high doses oral PEG. Pediatrics 2009;124:1108-15. [CrossRef]

13. Araghizadeh F. Fecal impaction. Clin Colon Rectal Surg 2005;18:116-9. [CrossRef]

14. Eitan A, Bickel A, Katz IM. Fecal impaction in adults: report of 30 cases of seed bezoars in the rectum. Dis Colon Rectum 2006;49:1768-71. [CrossRef]

15. Di Palma JA, Smith JR, Cleveland Mv. Overnight efficacy of polyethylene glycol laxative. Am J Gastroenterol. 2002;97:1776-9. [CrossRef]

16. Read NW, Abouzekry L, Read MG, Howell P, Ottewell D, Donnelly TC. Anorectal function in elderly patients with fecal impaction. Gastroenterology 1985;89:959-66. [CrossRef]

17. Lee-Robichaud H, Thomas K, Morgan J, Nelson RL. Lactulose versus Polyethylene Glycol for Chronic Constipation. Cochrane Database Syst Rev 2010:CD007570. [CrossRef]

18. Yuan R, Zhao GG, Papez S, Cleary JP, Heliotis A. Urethral obstruction and bilateral ureteral hydronephroses secondary to fecal impaction. J Clin Gastroenterol 2000;30:314-6. [CrossRef]

19. Vijayakumar C, Balagurunathan K, Prabhu R, Santosh Raja E, Amankumar S, Kalaiarasi R, et al. Stercoral Ulcer Not Al- ways Indolent: A Rare Complication of Fecal Impaction. Cureus 2018;10:e2613. [CrossRef]

20. Brown CD, Maxwell F, French P, Nicholson G. Stercoral perforation of the colon in a heroin addict. BMJ Case Rep 2017;2017:bcr2016218875. [CrossRef]

21. Earnest DL. Other diseases of colon and rectum. In: Sleisenger M, Fordtran J, editors. Gastrointestinal Diseases. 6th ed. Philadelphia: WB Saunders; 1998. p. 1990-2.

22. Engelberg M, Nudelman I, Korzets Z. Giant fecaloma with dolichomegasigma. Am J Proctol Gastroenterol Colon Rectal Surg 1982;33:9-12, 28.

23. Pfeifer J, Agachan F, Wexner SD. Surgery for constipation: a review. Dis Colon Rectum 1996;39:444-60. [CrossRef]

24. Lee SL, DuBois JJ, Montes-Garces RG, Inglis K, Biediger W. Surgical management of chronic unremitting constipation and fecal incontinence associated with megarectum: A preliminary report. J Pediatr Surg 2002;37:76-9. [CrossRef]

25. Gladman MA, Scott SM, Lunniss PJ, Williams NS. Systematic review of surgical options for idiopathic megarectum and megacolon. Ann Surg 2005;241:562-74. [CrossRef]

26. Stewart J, Kumar D, Keighley MR. Results of anal or low rectal anastomosis and pouch construction for megarectum and megacolon. Br J Surg 1994;81:1051-3. [CrossRef]

\section{Masif Fekal Impaksiyona Bağıı Gelişen Megarektum: Olgu Sunumu}

Fekal impaksiyon, kolon ve rektumda birikip normal peristaltik aktivite ile boşaltılamayan sertleşmiş fekal muhteviyat nedeniyle oluşur. Fekal impaksiyon, huzurevi sakinleri, nörolojik bozukluğu olan hastalar, psikiyatri hastaları veya kronik böbrek yetersizliği olan hastalar arasında sık görülür. Fekal impaksiyon, genellikle parmakla boşaltma, lavman ve müshillerle tedavi edilir. Laparotomi sadece komplikasyonlar ortaya çıkınca gereklidir. Biz burada kalın bağırsak obstrüksiyonu bulgularıyla başvuran 62 yaşında bir kadın hastada megarektuma sebep olan masif fekal impaksiyon olgusunu sunuyoruz. Bu çalışmanın amacı, bu klinik durumu kısaca gözden geçirmek ve bu olguların tedavi seçeneklerini irdelemektir.

Anahtar Sözcükler: Fekal impaksiyon; kabızlık; megarektum; mekanik bağırsak obstrüksiyonu. 